\title{
APROXIMACION A LOS COMPORTAMIENTOS SOCIALES Y A LA ALIMENTACION EN LAS MARISMAS DEL GUADALQUIVIR Y SU ENTORNO
}

Isabel GONZALEZ TURMO *

Las últimas décadas han presenciado un vertiginoso e incontrolado cambio de los hábitos alimenticios; los medios de comunicación y la imparable publicidad desplegada por las multinacionales de la alimentación han alterado la aparente estabilidad con que evolucionan procedimientos culinarios y formas de subsistencia repetidos durante décadas y aun centurias. Estas alteraciones afectan a las culturas más primitivas y a los rincones más recónditos de nuestro planeta y, desde luego, a la totalidad de nuestra comunidad autónoma, aunque de modo más acentuado a los medios urbanos que a los rurales. Aún así, entre estos últimos, existen zonas que, tanto por su peculiar ecosistema, como por el particular aprovechamiento que éste haya permitido a sus moradores, se han constituido en laboratorios de especial interés para el estudio de la alimentación desde un punto de vista antropológico. Es el caso de las Marismas del Guadalquivir y de su entorno y, en concreto, de algunas de las poblaciones que lo conforman, a saber, Almonte, Villamanrique de la Condesa, Trebujena y Sanlúcar de Barrameda, en las que se han realizado los trabajos que han permitido la consecución de algunas de las hipótesis que en este artículo se exponen ${ }^{1}$.

\section{LA SUBSISTENCIA EN UN MEDIO HOSTIL}

Comparten las Marismas del Guadalquivir con otros ecosistemas similares el háberse manifestado durante siglos al hombre como un territorio hostil e inútil a su explotación agrícola, permitiendo poco más que el aprovechamiento de su riqueza vegetal y faunística. Este estado de cosas ha posibilitado la perpetuación de formas de alimentación cuasi paleolíticas (caza, pesca y recolección), asimila-

* Antropóloga. Secretaria de la Comisión Internacional sobre Antropología de la Alimentación.

1. El trabajo de campo se ha realizado durante tres años consecutivos en las poblaciones mencionadas. 
das a otros hábitos, propios del medio agrícola colindante (cocina tradicional a partir de productos agrarios). La coexistencia espacial y temporal de estos dos sistemas nutritivos, aunados en una única dimensión alimenticia y en hábitos culinarios comunes, pervive todavía, aún cuando se esté produciendo una invasión del mercado por parte de procedimientos y, sobre todo, de materias primas foráneas. A modo de curiosa singularidad, que contribuye a diferenciar esta zona del resto de las comarcas andaluzas, se ha generado, pues, una prolongada coincidencia temporal de dos formas de alimentación pertenecientes, en principio, a épocas y sistemas económicos distintos, a saber, aquella que se fundamenta en lo que ofrece el medio natural y que consiste en la ingestión de lo obtenido de la caza de aves acuáticas y otros animales marismeños, de la pesca de río y de la recolección de plantas silvestres, huevos, caracoles, etc., todas ellas con un radio de difusión muy restringido espacialmente y limitado a grupos sociales de carácter marginal, junto con la que podríamos denominar alimentación tradicional, compartida con gran número de pueblos andaluces, que tiene su base en los potajes, pucheros, gazpachos, calderetas y fritos y cuyo mercado ha sido hasta hace unas décadas de ámbito regional, provincial o incluso comarcal. Frente a éstas, la alimentación industrial, constituida por productos como yogures, hamburguesas, salchichas, avecrem, salsas de botes o pizzas, ajenos todos a esta pohlación hasta hace poco más de quince años y cuya industria no pertenece, en muchos casos, a nuestra comunidad autónoma ni aún a la nacional, causa furor entre las nuevas generaciones y las amas de casa, incorporadas al mundo laboral $y$, en cualquier caso, escasas de tiempo que dedicar a la cocina.

Todo parece indicar, a primera vista, que se produce un receso de los usos alimenticios más primitivos y tradicionales, a favor de la nueva alimentación. Pero para comprender el alcance y las formas de articulación en que se desenvuelven estas transformaciones habría que precisar algunas de las características de la población estudiada, así como las del entorno al que se deben o en el que tienen lugar sus hábitos alimenticios. En primer lugar, se hace necesario diferenciar, tanto espacialmente, como en el desarrollo histórico de sus formas de subsistencia, a los moradores del interior de las Marismas y del Parque Nacional de Doñana, de los habitantes de las poblaciones circundantes. Los primeros han habitado un ecosistema, formado por dos espacios ecológicos claramente diferenciados y complementarios en lo que a su explotación por parte del hombre se refiere: EI Coto de Doñana y las marismas del Guadalquivir. El funcionamiento hidrológico de este territorio, ha posibilitado el potencial biológico que lo ha hecho famoso. Pero la hospitalidad ofrendada por el medio a la fauna, tanto permanente, como migratoria, no se ha correspondido con un trato similar para con el hombre. Las periódicas inundaciones del Guadalquivir, la insalubridad del 
medio, la imposibilidad de su aprovechamiento agrícola y el tradicional régimen de tenencia de la tierra ${ }^{2}$, acaparada en pocas manos que no le han dado otro uso, hasta fechas recientes, que el cinegético o, en todo caso, el del mantenimiento de ganadería vacuna y caballar, que necesita poca mano de obra y aún ésta no permanentemente afincada en las Marismas, han propiciado el que estos parajes hayan estado escasamente habitados desde que tenemos memoria histórica. Hasta mediados del presente siglo sus moradores permanentes eran pastores de ganado menor y guardas de fincas, además de los trabajadores temporales, que solían pasar en los caseríos y cortijos un máximo de quince o veinte días seguidos. Eran hombres que vivían de lo que el medio y sus pequeños cultivos producían, y que, incluso para el almacenamiento de agua o para conseguir la energía necesaria con que cocinar, tenían que ideárselas para sacar partido de lo único que se les ofrecía: su entorno, un medio hostil y duro al que conocían bien. En la actualidad la población es aún menor; de hecho, ha quedado reducida a un mínimo de caseros y de guardas de ICONA, mientras que los escasos trabajadores que acuden a las fincas, en su mayoría altamente tecnificadas, vuelven cada noche a sus respectivos pueblos. Es indudable que la forma de subsistencia de aquellos hombres, que vivían prácticamente incomunicados de los núcleos poblados, a los que tan sólo acudían una o dos veces al mes para comprar lo que llamaban el costo (lo que no podían cultivar ni atrapar directamente de la naturaleza: garbanzos, aceite, azúcar, etc...), era más dependiente del medio y de la periódica repetición de los ciclos ecológicos anuales, que la de los habitantes de los pueblos cercanos. En cuanto a éstos, puede decirse que constituían un eslabón intermedio entre ese sistema cuasi autártico y el que preponderaba en la mayoría de los pueblos del Bajo Guadalquivir, con unos procedimientos de comercialización de los productos alimenticios considerablemente uniformizados. Pues, si bien compartían con éstos la posibilidad de acceder regular y sistemáticamente al mercado de productos de procedencia agrícola o ganadera, por otra parte, podían adentrarse en las marismas para hacerse de una fuente de riqueza alimenticia de la que carecían la mayoría de los pueblos andaluces, a partir de las roturaciones del siglo XVIII y la consiguiente eliminación del llamado "pan de los pobres" ?.

Para entender en su verdadera dimensión histórica la importancia que para

2. García Arteaga, J. "Las Marismas: de anekumene a tierra con una proyección económica y social". Tesis sin publicar. Ojeda Rivera, J.F. "Organización del territorio en Doñana y su entorno próximo (Almonte). Siglos XVIII-XX”. Edita ICONA. Universidad de Sevilla. Departamento de Geografía. Madrid, 1987.

3. Sánchez Salazar, Felipa. "Extensión de cultivos en España durante el siglo XVIII". 2 tomos. Tesis Doctoral 16/86. Ediciones de la Universidad Complutense de Madrid. 
estas poblaciones ha tenido el acceso a este aporte proteínico complementario, así como su coexistencia con formas de alimentación tradicional más extendidas geográficamente, hay que considerar que más de la mitad de la población activa de algunos de estos pueblos era y es, ya desde el siglo XVI, jomalera ${ }^{4}$ y que, por lo tanto, el trabajo le era retribuido, desde estas fechas también, en dinero y en especies. Este pago en especies se haría en aquellos productos agrícolas que se cultivaban en terrenos del entorno de las Marismas y en los que aún hoy siguen existiendo, a pesar de los muchos cambios que se han producido, algunos cultivos similares a los de entonces: legumbres y, sobre todo, trigo, vid y olivar, la trilogía mediterránea, predominante en las comarcas cultivables al Norte y al Oeste de las Marismas. Pero aún así, es probable que, al igual que ocurre hoy en día, el jornal no fuera suficiente para adquirir la ración proteínica necesaria en la dieta de un trabajador adulto. Las marismas ofrecían, a pesar de las prohibiciones de sus propietarios, demasiado lejanos en la mayoría de los casos como para ejercer sus derechos legales con eficacia ${ }^{5}$, una variada gama de alimentos, que cada año y puntualmente estaban al alcance de quienes quisieran y necesitaran sufrir los rigores que implicaban su obtención. Este, pues, era el aporte complementario a una dieta básicamente constituida por pan, harina, legumbres, aceite, café, y, en el mejor de los casos, cerdo o cabra. Una variante, sin embargo, de esta situación relativamente uniforme la ha representado, al menos desde el siglo XVI, Sanlúcar de Barrameda que, tanto por su posición privilegiada en la Carrera de Indias, como por la posterior importancia que para su economía cobran la pesca ${ }^{6} \mathrm{y}$, ya entrado el siglo, el turismo, ha mantenido hábitos de alimentación adicionahles a los ya mencionados.

\section{TRANSFORMACION DE LOS HABITOS ALIMENTICIOS}

Este estado de cosas ha evolucionado a lo largo de los últimos veinte o treinta años de modo muy desigual: de una parte, el interior del territorio ha perdido definitivamente la peculiaridad de sus tradicionales prácticas alimenticias, como consecuencia del despoblamiento y de la proximidad con que ahora se ofrecen los núcleos urbanos, gracias a la mejora de las vías de comunicación; una vez prescritas las viejas formas de subsistencia que las hacían necesarias, las prácti-

4. Bernal, A.M. "Andalucía Occidental: economía rural, 1590-1765" en "Historia de Andalucía". Tomo VI. Editorial Planeta. Madrid, 1981, pp. 205-6.

5. García Arteaga, J. op, cit.

6. Muñoz Pérez, J. "La pesca en la desembocadura del Guadalquivir". Instituto de Estudios Gaditanos, Cádiz. 1972. 
cas alimenticias autárticas del pasado, aquellas cuya racionalidad consistía en el aprovechamiento y en la observancia de las exigencias del medio, se han disipado. Por sn parte, los pueblos, y sobre todo sus miembros más jóvenes, han asimilado los nuevos hábitos, de clara influencia urbana y procedencia industrial. Pero al mismo tiempo, se ha producido un resurgir de formas marginales de subsistencia, que suponen la recuperación, en algunos casos, de prácticas y técnicas casi perdidas (caracoleo, pesca de río, etc...), coincidiendo con los años de la crisis económica y la generalización del desempleo. Esta recuperación mantiene, sin embargo, importantes diferencias con respecto a los viejos procedimientos, pues si antes tenían como principal objetivo el abastecimiento del propio grupo familiar, aún cuando se vendiera parte de lo capturado o recolectado, en la actualidad, por el contrario, se suele comercializar la totalidad del producto.

Estos aspectos no alteran, sin embargo, los fundamentos culturales de la alimentación de estos pueblos y, de hecho, puede decirse que se simultanea la adopción de modos de alimentación industriales con el mantenimiento de hábitos tradicionales, sobre todo, en los modos de elaboración, sin que ello cree mayores desajustes tanto en la vida familiar como en el funcionamiento de los locales dedicados a ello. Pues, si bien es cierto que los más jóvenes prefieren, y en muchos casos exigen, hamburguesas, salchichas, refrescos y una amplia gama de vistosos dulces, envueltos en papel de celofán, también lo es que la adopción de nuevos productos se limita, en gran medida, a aquellos que no modifican los procedimientos culinarios en lo sustancial, como es el caso de las verduras o los pescados congelados, caldos concentrados, café en polvo, mayonesa de bote o margarina. Es indudable que estas mudanzas alteran el régimen nutritivo de la población, al igual que ocurre con el aumento en el consumo de productos lácteos y de fruta, pero no tanto los aspectos culturales de su alimentación, pues las técnicas, las recetas y la organización familiar y social en torno a ésta siguen siendo muy similares en lo fundamental a las de tiempos pasados, salvo para aquellos platos y acontecimientos que requieren de mucho tiempo de elaboración. En este sentido, podría afirmarse que la prisa generalizada, y en concreto la del ama de casa, es el principal motor de cambio de la alimentación pues la publicidad, aún cuando juegue un papel fundamental, no siempre consigue introducir sus productos en aquellos mercados, denominados "commodities" por los ingleses, en los que prima el precio por encima de la marca. ${ }^{7}$.

Es, por lo tanto, indudable que se han perdido definitivamente aquellos platos y procedimientos que más ligados y restringidos estaban al interior del territorio;

7. Jordana Butticaz, J. "La nueva agricultura española" en "Papeles de Economía Española". Madrid, 1980. 
del mismo modo han desaparecido teorías nutricionales y curativas, que buscaban en remedios naturales la superación de los males más diversos; el mismc destino han seguido los regímenes y las prohibiciones alimenticias que se recomendaban para la buena marcha de los embarazos y de la salud de las lactantes Todos ellos han dejado de existir, cuando el modo de subsistencia y la necesidac que los requerían ha cedido el paso a modernos y generalizados procedimientos. en los que se interpone un especialista -ya sea en forma de médico o de voz $€$ imágenes que, desde detrás de la pantalla del televisor, inducen a un determinadc tipo de consumo- y a partir del momento en que cualquier producto se puede adquirir en un establecimiento cercano, sin necesidad de conseguirlo directamente, allí donde la naturaleza lo ofrece, para después tenerlo que reciclar y preparar hasta hacer posible su ingestión. Los medios de comunicación, por otra parte. han uniformado las pautas de consumo de los más jóvenes, que, de este modo, enarbolan la bandera de sus gustos frente al resto de las generaciones, saltando por encima de diferencias sociales o medioambientales. Pero parece de todo punto incuestionable que esta aparente equiparación social en el consumo no podrá prolongarse, en el mejor de los casos, más allá de unos años para cada generación, pasados los cuales cada cual tendrá que adaptarse a la evidencia de las limitaciones socioeconómicas que su posición le imponga, al igual que se verá en la necesidad de reestructurar su alimentación más allá de los refrescos o las hamburguesas, si pretende desarrollar la actividad propia de una persona adulta.

\section{TENDENCIAS Y DISPOSICIONES REGISTRABLES}

Por todo ello, podría concluirse que las pautas de comportamiento que en la zona se observan, en cuanto a la transformación de los hábitos alimenticios, parecen indicar una tendencia a la adopción de nuevos productos, junto a una relativa inalterabilidad de las prácticas culinarias, a la vez que se van conformando determinados subgrupos de hábitos alimenticios que permanecen, por el momento, anclados en grupos sociales concretos, ya sea en razón de su edad, como es el caso de los jóvenes, o de su ligazón a profesiones o modos de subsistencia muy relacionados con la obtención de determinados productos alimenticios, como es el caso de los marineros, pescadores, furtivos, etc... Los hábitos alimenticios evolucionan muy lentamente; máxime entre una población rural de tradición culinaria rica en materias primas, pero con unos procedimientos de elaboración muy sencillos y populares, incluso entre las clases más altas, cuyas mujeres, al igual que las marineras o las campesinas, y aún cuando utilicen 
productos mucho más caros, improvisan a partir de recetas repetidas durante generaciones, haciendo caso omiso de libros de cocina y de programas radiofónicos o televisivos, que poco o nada añaden a unos gustos muy consolidados. Y es que, curiosamente, el gusto alimenticio, quizá por lo que tiene de inmediato y fisiológico, tiende a buscar una total conformidad entre la realidad y el deseo, al margen de otras consideraciones de diferenciación social, de modo que la mayoría de la gente, y siempre y cuando se alcancen los mínimos necesarios que excluyan el límite de necesidad marcado por el hambre, lo que prefiere es precisamente aquello que puede comer y que en su casa le ponen cada día por delante. Poco tienen, pues, que ver los hábitos y los criterios marcadores del gusto alimenticio de los habitantes del entorno de las Marismas, aún a pesar de cuántos productos industriales se hayan podido introducir en el mercado local, con aquellos que determinadas clases urbanas han constituido en un ejercicio culto que como tal funciona como baremo de diferenciación social. En nuestro medio, este tipo de diferenciación se perfila, en todo caso, en base a la cantidad o la calidad de los alimentos y, sobre todo, a través de aquellos acontecimientos sociales y festivos, donde a la vista de todos o casi todos se mide la capacidad de representación de cada cual y en los que cada alimento, y su precio, contiene un significado más cercano a una calificación evaluadora, en este caso de prestigio social, que fundamentado en sus verdaderas cualidades nutritivas e incluso en los gustos de los comensales. 


\section{BIBLIOGRAFIA}

AGUDO TORRICO y otros: Introducción a la cultwal material de carácter tradicional en la provincia de Sevilla. Ediciones Gever, Sevilla, 1984.

CHAMPAN, ABEL Y BUCK, WALTER J. La España inexplorada. Junta de Andalucía. Consejería de Obras Públicas y Transporte, Sevilla, 1989.

EQUIPO 28: El Rio, Sevilla, 1985.

EQUIPO 28: Plan de Promoción Turistico y Cultural de Sanlácar de Barrameda, Sevilla, 1988.

FERNANDEZ, J. ANTONIO: Guia de Campo del Parque Nacional de Doñana, Editorial Omega, Barcelona, 1982.

FERRARO GARCIA, FRANCISCO: Informe economico del Plan General de Ordenación Urbana de Almonte, Sevilla, 1984.

GARCIA ALVEAR. MARIANA: Los ranchos de Doñana, Consejería de Obras Públicas y Transporte, Sevilla, 1985.

GRANDE COVIAN, FRANCISCO: Las Marismas del Guadalquivir y su rescate, Ministerio de Agricultura, Madrid, 1967.

HERNANDEZ RAMIREZ. JAVIER y PLAZA CORRAL, GERARDO: Los ganaderos de Doñana y su entorno, (inédito).

JUNTA DE ANDALUCIA. Caracterización socioeconómica de las comarcas andaluzas, Sevilla, 1981. JUNTA DE ANDALUCIA. Consejería de Obras Públicas y Transportes. PDTC de Doñana y su entorno, Sevilla, 1989.

LEROI-GOURHAN, ANDRE: El medio y la técnica, Taurus, Madrid, 1989.

LUJAN, NESTOR. Historia de la Gastronomía, Plaza y Janés, Sabadell, 1988.

LUJAN, NESTOR Y PERUCGO, JUAN: El libio de la cocina española. Ed. Planeta, Barcelona, 1972.

LUQUE, AQUILINO: Doñana, Publicaciones del Ministerio de Educación, Madrid, 1977.

MADOZ. PASCUAL: Diccionario geográfico-estadístico-histórico de Andalucía, Ed. Andaluzas Unidas, Sevilla, 1986.

MARTINEZ LLOPIS, MANUEL: Historia de la gastronomía española, Alianza Editorial, Madrid, 1989.

MAS, JOSE: Luna y sol de marismas, Imprenta de Galo Sáenz, Madrid, 1930.

MUÑOZ PEREZ. JOSE: La pesca en la desembocadura del Guadalquivir. Instituto de Estudios Gaditanos, Cádiz, 1972.

OJEDA RIVERA, J.F.: Organización del territorio en Donana y su entorno próximo (Almonte). Siglos XVIII-XX, Edita ICONA, Universidad de Sevilla, Departamento de Geografía, Madrid, 1987.

PABLOS, MERCEDES DE y SAENZ, EMILIO: La Vega y la Marisma. Monte de Piedad y Caja de Ahorros de Sevilla. Sevilla, 1985.

PALENZUELA, PABLO: El componente marginal en la renta del jornalero andaluz, Revista de Agricultura y Sociedad, 1987.

VARELA, GREGORIO: "Actitudes de la población andaluza ante algunos problemas alimenticios". Anales de Sociología. 4-5 (pp. 43-61).

ZOIDO, FLORENCIO: "Isla Mínima. Aspectos geográficos-agrarios". Anales de la Universidad Hispalense, Sevilla, 1973. 